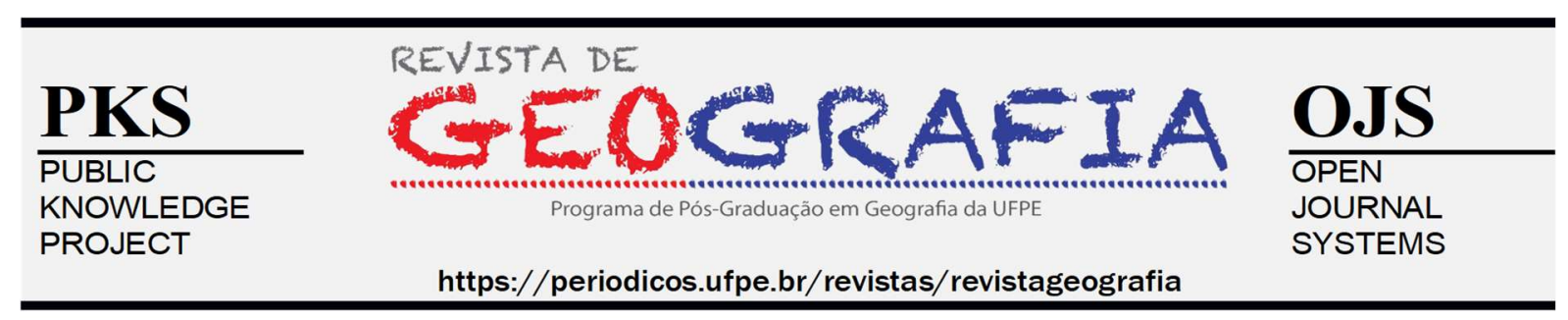

\title{
POTENCIAL DE USO DO SOLO URBANO EM CIDADE MÉDIA: UMA ANÁLISE DA CIDADE DE MONTES CLAROS/MG
}

\author{
Carla Milena de Moura Laurentino, Marcos Esdras Leite ${ }^{2}$, Lucas Augusto Pereira da \\ Silva $^{3}$, Samuel Carlos Santos Marques ${ }^{4}$
}

\footnotetext{
${ }^{1}$ Universidade Estadual de Montes Claros - UNIMONTES. E-mail: carlamilenaml@gmail.com

${ }^{2}$ Universidade Estadual de Montes Claros - UNIMONTES. E-mail: marcosesdrasleite@gmail.com

${ }^{3}$ Universidade Estadual de Montes Claros - UNIMONTES. E-mail: lucaskaio1605@gmail.com

${ }^{4}$ Universidade Estadual de Montes Claros - UNIMONTES. E-mail: samuel35marques@gmail.com
}

Artigo recebido em 07/10/2019 e aceito em 03/06/2020

\begin{abstract}
Resumo: O crescimento populacional das cidades tem provocado o uso demasiado do solo urbano. Este uso, atrelado à especulação imobiliária, ocasiona diversos problemas ambientais, sobretudo no que tange à retirada da vegetação natural. Este trabalho propôs analisar o potencial de uso do solo urbano da Cidade de Montes Claros, situada no Norte de Minas Gerais. Para essa análise, dotou-se do uso de técnicas de sensoriamento remoto e sistemas de informações geográficas. O mapeamento destacou que áreas não adequadas para uso residencial estão sendo utilizadas para atender os interesses da especulação imobiliária e de moradores de alta renda, originando condomínios direcionados a população de maior poder aquisitivo. Assim, o presente trabalho trouxe, com o uso das geotecnologias, informações importantes para compreender o ordenamento do uso do solo urbano, notadamente em cidades com considerável crescimento populacional.
\end{abstract}

Palavras-Chave: Sensoriamento Remoto, Geotecnologias, Código Florestal e Condomínios de Alto Padrão.

\section{POTENTIAL OF URBAN SOIL USE IN MEDIUM CITY: AN ANALYSIS OF THE CITY OF MONTES CLAROS / MG}

\begin{abstract}
The population growth of cities has an excessive use of urban land. This use linked to real estate speculation causes several environmental problems, mainly with regard to the removal of natural vegetation. This work proposes to analyze the potential of urban land use in the City of Montes Claros, in the North of Minas Gerais. For this analysis, you can use remote sensing techniques and geographic information systems. The highlighted mapping of areas not used for residential use is being used to serve the interests of real estate speculation and high-income residents, giving rise to high-income condominiums. This work brought, using geotechnology, important information in spatial urban land use, notably in cities with population growth.

Keywords: Remote Sensing, Geoprocessing, Forest Code and High Standard Condominiums.
\end{abstract}




\section{Introdução}

A urbanização, é um fenômeno que tem intensificado em diversas partes do mundo, tendo como fator intrínseco, o crescimento populacional, pois, com este fato, surgem demandas por espaço. Isso corrobora com novos modelos e formas de vivência, sobretudo nas cidades, as quais possuem suporte biológico e material para as populações, e que nas últimas décadas, em específico no Brasil, passaram por um processo de crescimento significativo (SANTOS e FERRAZ, 2020).

Neste contexto, a produção do espaço urbano nas cidades deve ser vista num prisma crítico, pois, em muitos casos, o parcelamento do solo não se norteia em função das necessidades habitacionais como um bem comum, e sim, tendo como impulsionador, as demandas orientadas pelo capital (BORIN e MEIRELES, 2020).

Dessa forma, o uso do solo urbano reflete diretamente à essas nuances ditadas pelo modelo capitalista vigente. Por exemplo, a supervalorização de áreas com densidade vegetal (áreas verdes) nas cidades, corresponde a um traço do mecanismo que envolve a dinâmica do capital na produção do espaço urbano.

A pressão urbana sobre os ecossistemas é uma preocupação aparente no âmbito das cidades (RODRIGUES et al., 2019). A perda de vegetação acarreta em decréscimos de serviços ecossistêmicos e, consequentemente, na qualidade de vida nas cidades. Com isso, instrumentos da legislação ambiental podem ser basilares na limitação de ocupação urbana em áreas de preservação, como, por exemplo, o Novo Código Florestal, instituído pela Lei 12.651/12, que possui função ambiental de preservar os recursos hídricos, o contexto paisagístico, a estabilidade dos aspectos geológicos e a biodiversidade, bem como facilitar os fluxos de fauna e flora, proteger o solo e assegurar o bem-estar das populações humanas.

Mesmo com essas instrumentalizações de cunho jurídico, notadamente há descumprimento das mesmas, principalmente por parte de pessoas com elevado poder aquisitivo, sobretudo com a inserção de condomínios de alto padrão em Áreas de Preservação Permanente - APP (REIS et al., 2020).

$\mathrm{Na}$ cidade de Montes Claros - Minas Gerais (MG), os condomínios residenciais destinados à população de alta renda estão concentrados na zona oeste da cidade, em áreas consideradas irregulares ambientalmente, com declividade acima de $45^{\circ}$ e classificadas como ambientes de vulnerabilidade muito alta (SILVA, 2019). Esse último fator é crítico, 
haja vista que o aceleramento da perda vegetal nesses ambientes leva a degradação, poluição dos corpos hídricos e intensificação do escoamento superficial (SILVA et al., 2016; FRANÇA e BARBOSA, 2019). Nessa perspectiva, ações de planejamento do uso do solo urbano devem ser tomadas, com finalidade de cumprimento da legislação, assegurando a preservação da cobertura vegetal, buscando penalizações aos moradores sob condições de irregularidade ambiental.

Uma opção pertinente para auxiliar nesse planejamento, é o uso de técnicas de sensoriamento remoto e geoprocessamento, principalmente considerando a agilidade, o baixo custo e a facilidade no manuseio dessas técnicas. Estudos têm utilizado essas técnicas, e apontaram, principalmente o potencial do uso do solo urbano, identificando áreas propícias para expansão urbana, ocupação residencial, áreas em irregularidade, dentre outros aspectos (PEDRON et al., 2006; SOUZA et al., 2014; CAMPOS et al., 2016).

Assim trabalho tem como objetivo, analisar o potencial de expansão residencial na cidade de Montes Claros/MG, com técnicas de sensoriamento remoto e geoprocessamento. Montes Claros é uma cidade média localizado no norte do estado de Minas Gerais, sendo centro polarizador da dinâmica econômica da região, sobretudo por possuir concentração de atividades econômicas (serviços e empresas) atrativas para os demais municípios. Salientase, ainda, que essa área de estudo, definida como cidade média, apresenta crescimento acima da média nacional, o que torna este trabalho essencial para entender os impactos deste crescimento no contexto da expansão urbana (LEITE, 2011).

Existem estudos que tiveram como finalidade a análise da dinâmica de expansão urbana (FRANÇA; SOARES, 2007), habitações sociais (FRANÇA; BARBOSA, 2019), mecanismos de segregação espacial (LEITE; BATISTA; CLEMENTE, 2010), uso e cobertura do solo urbano em Montes Claros (LEITE et al., 2014). Entretanto, não se tem estudos com aplicações de geotecnologias para avaliar o potencial de expansão uso do solo urbano, o que é d grande importância para os tomadores de decisões. Esse estudo buscou preencher essa lacuna no contexto científico para a cidade de Montes Claros. 


\section{Materiais e Métodos}

\section{Caracterização da Área de Estudo}

A cidade de Montes Claros está localizada na região Intermediária e Imediata de Montes Claros (IBGE, 2017), no norte do estado de Minas Gerais, entre as coordenadas 16'45' e 16'40', (S)43'52', e 43'37' (O) como visualizada na figura 1. A cidade é composta, desde 2016, por 19 regiões de planejamento. Essas regiões foram efetivadas através do Decreto Municipal N 3.393 de 2016. Salienta-se que essas regiões são oriundas da proposta apontada por Leite (2006).

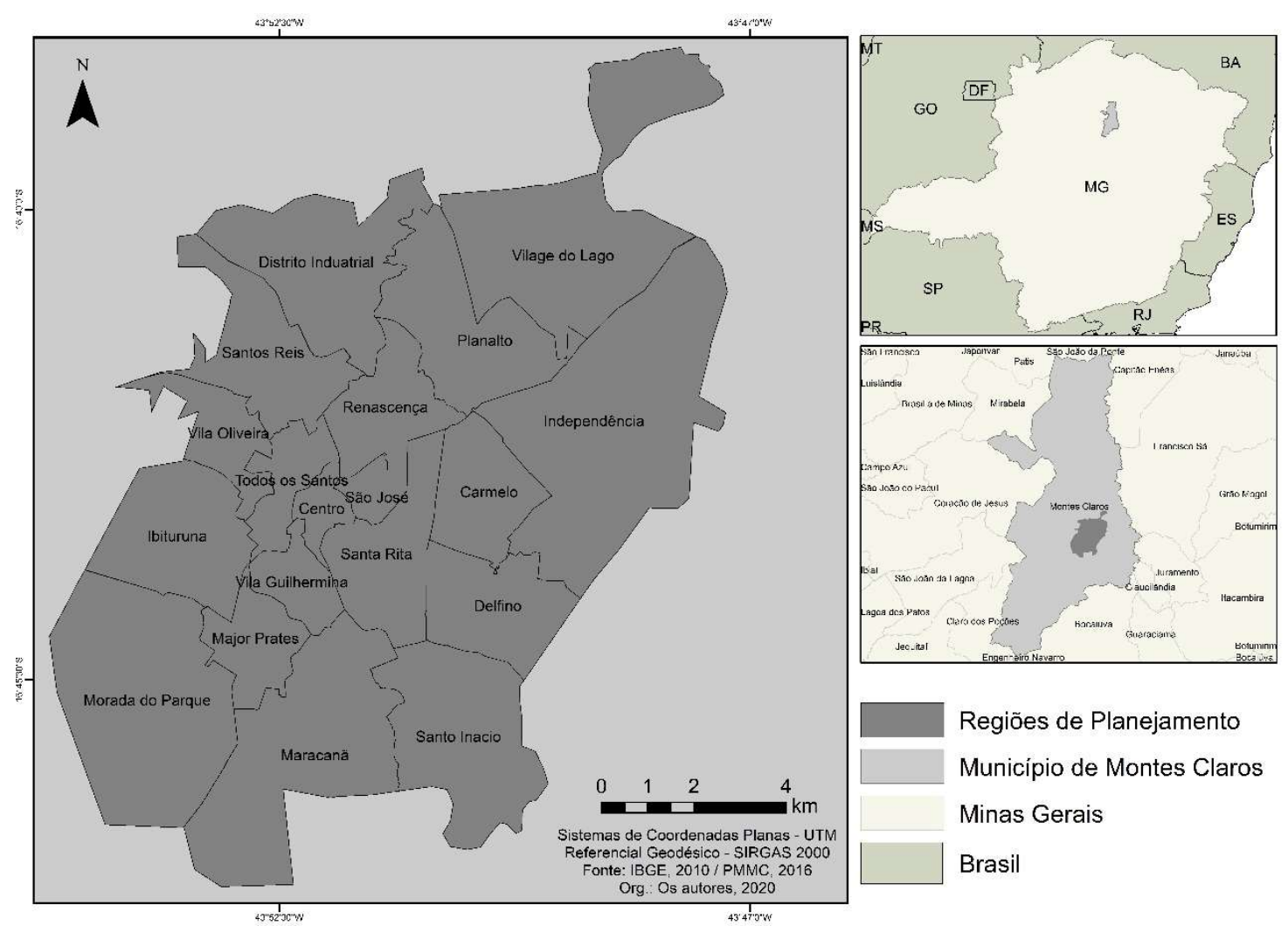

Figura 1 - Cidade de Montes Claros, no Município de Montes Claros, Norte de Minas Gerais, Brasil. Fonte: Os autores, 2020.

Em conformidade com Prefeitura Municipal de Montes Claros - PMMC (2016), menciona-se que os objetivos dessa divisão são: busca de melhor qualidade de vida para a população, considerando a eficiente organização do espaço urbano, além de construir um 
ambiente social favorável à convivência harmônica e saudável entre os munícipes. Dessa forma, trata-se de um elemento importante na gestão municipal.

Do ponto de vista demográfico, menciona-se que Montes Claros possui 404 mil habitantes (IBGE, 2018), possuindo um índice de desenvolvimento humano municipal (IDHM) é de 0,770 (IBGE, 2010). É oportuno apontar que houve acréscimos em escala temporal neste índice para Montes Claros, de 33,25\% e 14,16\%, respectivamente quando se compara com os dados de 1991 e 2000 (LEITE, 2011).

No contexto físico, destaca-se que o clima da área de estudo é tropical quente semiúmido (LEITE, 2018). No aspecto Geológico, destacam-se as unidades: Cobertura Superficial Indiferenciada, Grupo Urucuia, Formação Lagoa do Jacaré, Formação Serra da Saudade e Serra de Santa Helena (SIMÕES, 2015). Quanto ao relevo, é oportuno destacar os aspectos morfométricos da área, com elevações que variam de 579 a 916 metros, e declividade de 0 a 54,42\% (WERNER, 2001). No tocante à pedologia, há predominância de domínios de Latossolos (UFV, 2010). No que diz respeito à composição vegetacional, na área de estudo há predomínio de Cerrado e Floresta Estacional Decidual (LEITE et al., 2018).

\section{Procedimentos Técnicos e Operacionais}

Para execução deste trabalho foram seguidas algumas etapas operacionais conforme visualizado na figura 2, que variam da aquisição dos produtos cartográficos, passando pela análise computacional até a observação em campo para confrontação do resultado virtual com a realidade local.

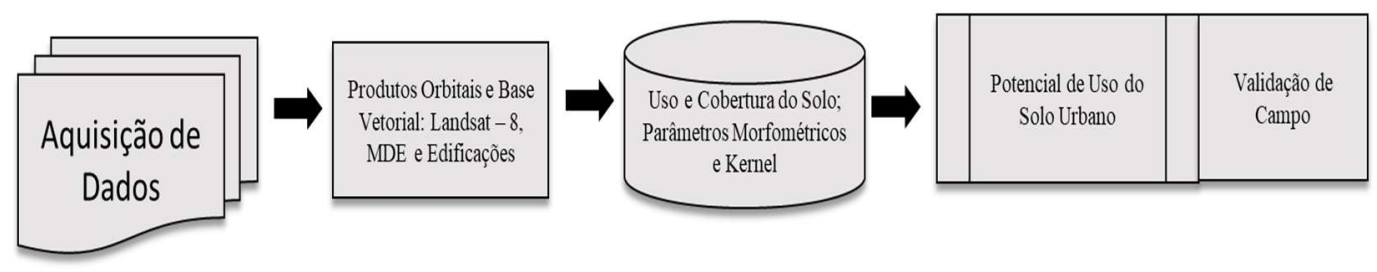

Figura 2 - Fluxograma das etapas operacionais. Fonte: ROY (2014); WERNER (2001); PMMC (2016). 


\section{Uso e Cobertura do Solo}

Os produtos utilizados nessa etapa, foram disponibilizados pela Agência Aeroespacial e Serviço Geológico dos EUA. Utilizou-se um pacote de imagens do sensor OLI (Operational Terra Imager), abordo do satélite Landsat 8. Referente à órbita e ponto 218/072. A imagem é do dia 16/07/2018.

Para o objetivo de mapear o uso e cobertura do solo, houve necessidade do processamento dos intervalos dos espectros do visível (entre 0,45 a 0,67 цm), infravermelho próximo (0,85 a 0,88 цm), e infravermelho médio (1,57 a 1,65 цm). Salienta-se que esses canais possuem resolução espacial de 30 metros (ou seja, a capacidade de distinguir os alvos na superfície restringe-se à essa célula mínima) e temporal de 16 dias.

Inicialmente, necessitou-se da etapa de pré-processamento, a qual, contempla a conversão de Números Digitais (ND) em valores físicos. Isso, porque as imagens obtidas, do satélite Landsat - 8 (sensor OLI), são disponibilizadas em ND, ou seja, valores binários. Para o mapeamento de uso e cobertura do solo, necessita-se dos dados em reflectância. A reflectância representa a razão entre a irradiância e radiação refletida pela superfície. Através da equação 01, realizou-se a conversão de ND em reflectância:

$$
\rho \lambda, b=\frac{H \rho Q C A L+A \rho}{\operatorname{ESUN}(\lambda) \cos (\theta S E)}
$$

Em que $H p$, representa o fator multiplicativo, Qcal são pixels quantizados da imagem, Ap, o fator aditivo, ESUN, a irradiância no topo da atmosfera e $\operatorname{Cos}(\theta S E)$ é o cosseno no ângulo de elevação do Sol. O fator multiplicativo representa a ascendência da relação linear entre níveis digitais e radiância, enquanto o fator aditivo, compreende aos valores iguais a zero na relação dos níveis digitais com a radiância. A irradiância dá a noção do montante de radiação que entra no sistema (no espectro reflexivo) para cada banda. E o cosseno da elevação do Sol, apresenta o status de inclinação.

Com os dados convertidos em reflectância, pode-se dar início ao processo de classificação supervisionada, dotando do algoritmo MaxVer (máxima verossimilhança), através do software $E R D A S$, versão 14. Este algoritmo atua com a interação pesquisador/máquina, em que, insere-se as amostras coletadas na cena, e, o maxver agrupa 
àquelas com maior semelhança espectral (SILVA et al., 2020). Dessa forma, estabeleceu-se as seguintes classes: Área Ocupada, Vegetação, Sem Cobertura Vegetal e Água.

\section{Parâmetros Morfométricos}

Inicialmente, obteve o Modelo Digital de Elevação (MDE) no sítio eletrônico do Serviço Geológico do EUA (ROY, 2014). Este produto possui resolução de 30 metros, equivalente a resolução das imagens do Landsat-8. Com o MDE disponível, aplicou-se a ferramenta Fill, com intuito de retirar as imperfeições do raster (vazios e erros). Na sequência, houve a classificação da hipsometria. Com este parâmetro, foi possível estabelecer a declividade, através da ferramenta Slope. Esses dois parâmetros representaram de maneira simplificada as variações do relevo da cidade de Montes Claros. Salienta-se o uso da plataforma Arcmap, do software ArcGis, versão 10.2.

\section{Kernel}

O estimador de densidade, o Kernel, foi aplicado em função dos pontos de edificações da cidade estudada. Salienta-se que esta base de dados, foi fornecida pela Prefeitura Municipal de Montes Claros. Este procedimento foi realizado na plataforma Arcmap, do software ArcGis 10.2, através da ferramenta Kernel Density. Este estimador de densidade, insere raios de abrangências em relação aos pontos inseridos nele. Aplica-se uma função matemática de 1 , na posição do ponto, e 0 na fronteira da vizinhança. $O$ valor apontado para a célula é dado em função da soma dos valores sobrepostos e dividido pela área de cada raio (SILVERMAN, 1986; NEMIROVSKY et al., 2018). Com isso, obteve-se um mapa de densidade construtiva para a cidade de Montes Claros.

\section{Potencial de Uso do Solo Urbano}

O potencial de uso do solo urbano, foi realizado com base em Franco (2011) e Souza et al., (2014). Por meio dos rasters de declividade e hipsometria (os quais deram a noção do relevo), densidade construtiva (que estimou as áreas com concentrações de edificações na 
cidade) e o uso e cobertura do solo (representou o status de cobertura física da superfície), foi possível obter o mapeamento do potencial de uso do solo urbano, conforme Equação 02:

$\underline{\text { (Declividade+Hipsometria+Uso e Cobertura do Solo+Densid } \quad \text { Construtiva) }}$ 4

Por fim, obteve-se o produto final, com 3 classes: Áreas adequadas para o uso do solo urbano, em que apresenta o relevo mais aplainado, maior concentração urbana e pouca vegetação; Áreas não adequadas, são áreas que contém a declividade mais acentuada e são áreas de APP; E áreas com potencial de uso do solo urbano, são áreas que apresentam o relevo adequado (áreas planas) para serem construídas. Salienta-se que, esse mapeamento foi validado em campo, conforme será demonstrado no decorrer dos resultados e discussão, a seguir.

\section{Resultados e Discussão}

\section{Distribuição Espacial dos Aspectos Socioeconômicos e Demográficos}

Montes Claros é conhecida, em âmbito regional, como principal polo urbano dinamizador de ofertas de serviços norte mineiro. No contexto educacional, há universidades nas esferas Estadual e Federal, bem como instituições privadas de ensino; no contexto de saúde, em que recebe pessoas de vários municípios norte mineiros, para atendimentos diversificados; além disso, há ampla oferta no setor comercial (CAMPOS et al., 2018; BOLAY, 2019; BOLAY e KERN, 2019; CRUZ et al., 2020).

Nessa seção, foram abordadas duas variáveis essenciais para o entendimento da dinâmica de ocupação do solo urbano de Montes Claros, a renda per capita por região de planejamento e o número de moradores como visualizada na figura 3. 


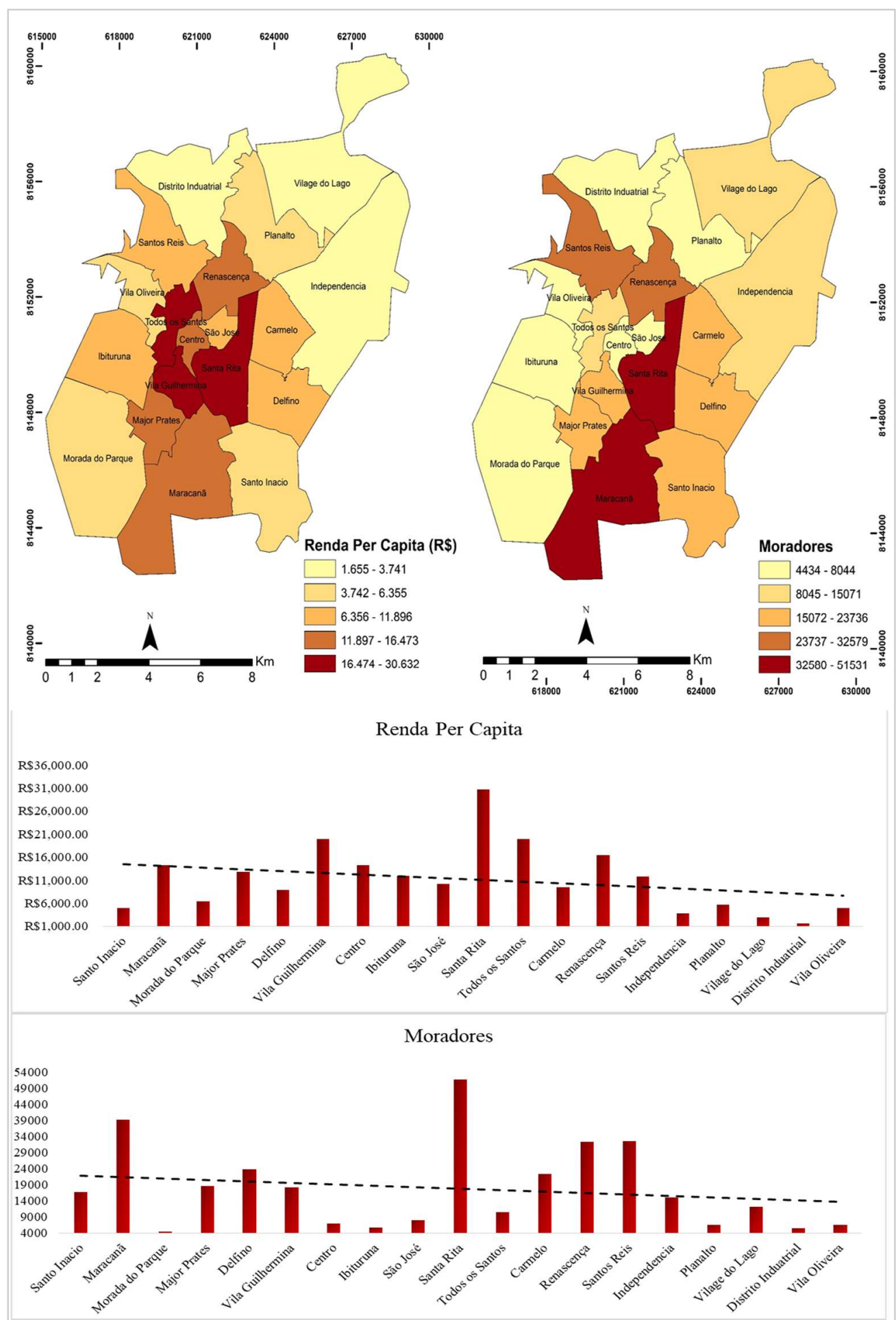

Figura 3 - Renda Per Capita e Número de Moradores por Região de Planejamento. Fonte: Os autores, 2020.

Observa-se que as maiores rendas per capita, entre $\mathrm{R} \$ 16.474$ e $\mathrm{R} \$ 30.632$, estão situadas nas porções centrais de Montes Claros, sendo Vila Guilhermina (com R\$19.929), 
Todos os Santos ( $\mathrm{R} \$ 1$ 19.867) e Santa Rita (com R \$ 30.632). As regiões com menores rendas, localizam-se nas porções noroeste (Distrito Industrial, com R\$ 1.655), Norte (Vilage do Lago, com R\$2.73) e Nordeste (Independência, R\$3.740). A amplitude entre a maior renda e a menor, é de $95,40 \%(\mathrm{R} \$ 28.977)$, mostrando assim a disparidade no que se refere à renda per capita em Montes Claros.

Na região de planejamento do Ibituruna menciona-se que a renda per capita é de R\$ 11.986, e salienta-se que o número de moradores se insere na classe com menores valores (4434 e 8044 pessoas, respectivamente), mostrando assim, uma relação inversamente proporcional. Essa correlação inversa está intimamente relacionada com o preço do solo urbano, pois, é sobremaneira elevado nessa região, o que desencadeia em um público exclusivo de moradores (BATISTA et al., 2019).

Buscando compreender melhor a relação entre renda e número de moradores notouse que há uma correlação de 38,70\% (e 34,90\% ajustada), considerada moderada. No entanto, observou-se casos específicos que tenderam a decrescer o modelo linear de determinação. Figura 4, a seguir.

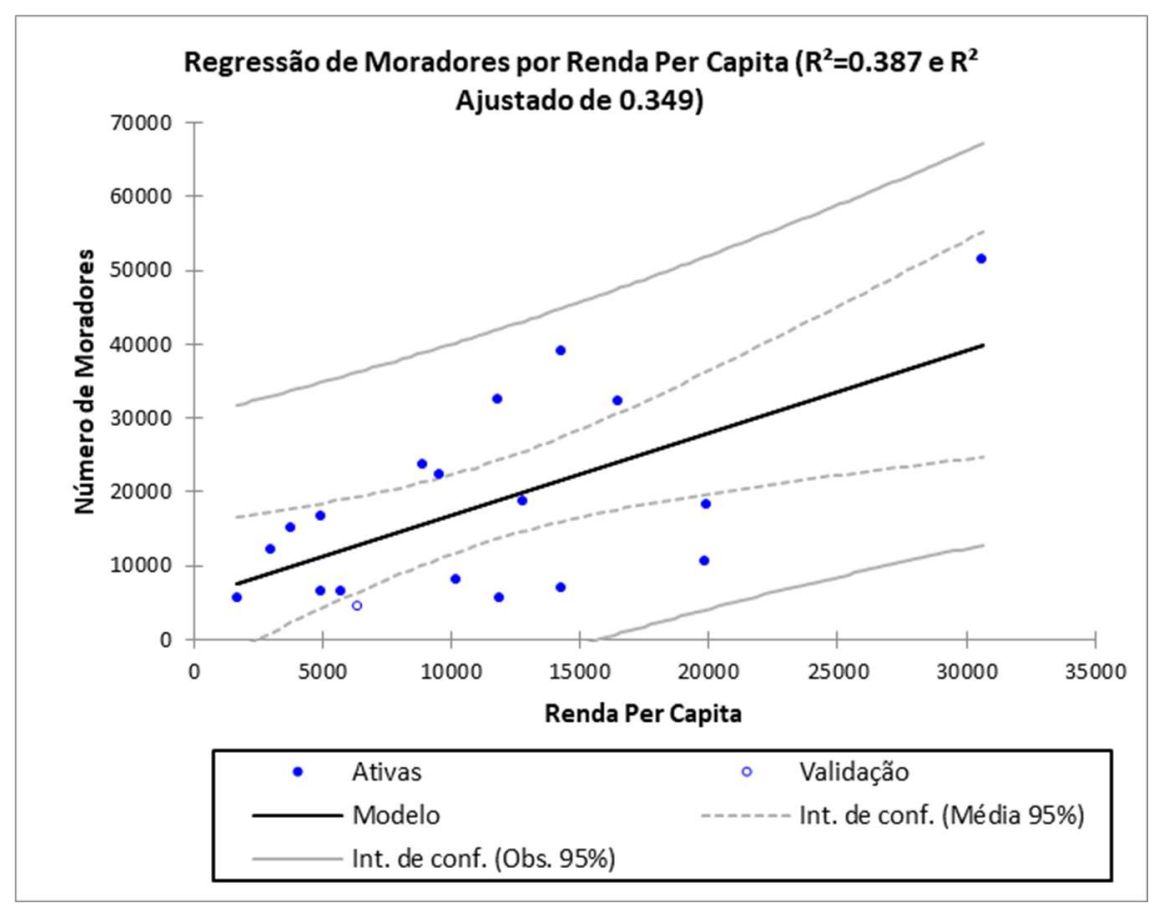

Figura 4 - Correlação entre Renda Per Capita e Moradores. Fonte: Os autores, 2020.

Em alguns casos, observa-se que há, de fato, sinergia entre essas variáveis, sobretudo nas regiões centrais, em que, nota-se maiores rendas per capita e maior número de Laurentino e et al, $2020 \quad$ ISSN 0104-5490 136 
moradores, e, isto está intimamente ligado às concentrações de serviços e empreendimentos. Outrora, nas regiões periféricas, a correlação é fraca, sobretudo por haver maior concentração de moradores e menor distribuição de renda per capita.

Este fato, se dá, sobretudo em função da baixa demanda de serviços e investimentos nessas áreas. É possível, ainda, apontar relação com preço da terra, visto que o valor da terra nessas áreas é relativamente baixo, ao comparar com regiões centrais e a sudoeste de Montes Claros (PEREIRA et al, 2019).

\section{Análise Integrada das Disposições Ambientais da Cidade de Montes Claros}

Esta etapa do trabalho, dedica-se a apresentar os aspectos físicos que serviram de parâmetros de entrada para o mapeamento do potencial de uso do solo urbano em Montes Claros. As variáveis necessárias foram: uso do solo, declividade, hipsometria e densidade construtiva. Entende-se que a disposição do uso do solo e densidade construtiva, possuem relação intrínseca com a morfometria, notadamente a declividade e a hipsometria (TEIXEIRA et al., 2020). Dessa forma, a análise integrada desses elementos torna-se essencial para organização e planejamento urbano.

Nesse sentido, observou-se que a maior parte da área urbana (91,18\% da área), encontra-se entre os intervalos de 0 a 9,82\% de declividade, localizando, nessa área, as regiões do Renascença, Todos os Santos, Centro, Vila Guilhermina, Major Prates, Santa Rita, Carmelo e Delfino, que apresentam maior concentração de edificações. Em contrapartida, $8,82 \%$ da cidade localiza-se sob uma área com declividade mais acentuada, entre os intervalos de $19,63 \%$ a 34,15\% conforme visto no mapa A da Figura 5. Essas áreas são referentes às regiões de planejamento do Distrito Industrial, Santos Reis, Vila Oliveira, Ibituruna e Morada do Parque.

As cotas mais elevadas encontram-se nas regiões periféricas a sudoeste e sudeste da cidade, as quais compreendem a área tombada da Serra do Mel, de acordo com o decreto municipal n³.467,29 (2016), é uma área de proteção, que não pode ser destruída ou descaracterizada. Essas regiões possuem 2,52\% entre os intervalos de $725 \mathrm{~m}$ a $811 \mathrm{~m}$ de altitude, e $4,45 \%$ estão entre $811 \mathrm{~m}$ a $916 \mathrm{~m}$ de altitude. Salienta-se que, devido à amenidade ambiental e boa localização, as regiões de planejamento do Ibituruna e Morada do Parque 
possuem um dos preços de terra mais elevado de Montes Claros (FRANÇA, 2015; GALVÃO, 2018).

Apesar da baixa densidade construtiva do Ibituruna e Morada do Parque, nota-se a intensificação do processo urbano nessas regiões que se localizam no sopé da Serra do Mel (FRANÇA, 2015), o que, em parte dessas regiões, apresenta descumprimento com a lei 12.651, de 2012, (Novo Código Florestal) desprotegendo áreas de proteção ambiental (APP), além da pressão do capital e do poder privado para a ocupação desses lugares.

Em contrapartida, a maior parte da cidade, ou seja, 70,35\% está entre os intervalos de $597 \mathrm{~m}$ a $672 \mathrm{~m}$ de altitude. Sobre essas áreas, estão as regiões de planejamento do Centro e adjacentes, no sentido norte, leste e sul. Assim, essas regiões apresentam elevado índice de edificações e possuem poucos espaços vazios.

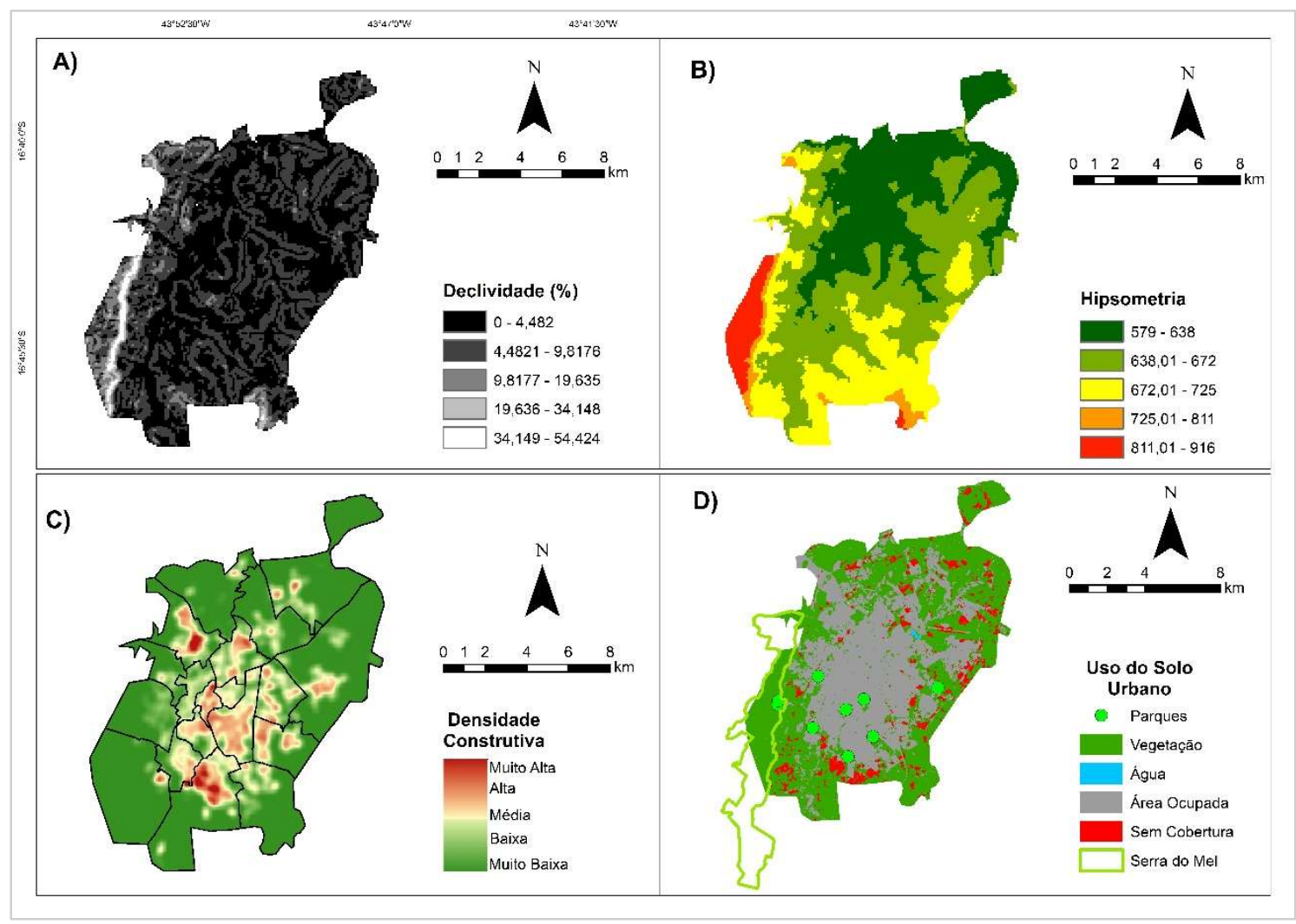

Figura 5 - Declividade, Hipsometria, Densidade Constritiva e Uso do Solo Urbano. Fonte: Os autores, 2020.

Quanto ao uso do solo visualizado no mapa D, Figura 5, a ocupação antrópica representa 40,54\% da cidade em análise. Essa ocupação concentra-se nas áreas mais centrais, 
onde se tem o relevo aplainado, que facilita o acesso e o desenvolvimento de atividades urbanas, o que é corroborado com na literatura científico, visto que nesses ambientes há maior concentração de atividades comerciais, residenciais e industriais (LEITE et al., 2014; RIFFEL e GUASSELLI, 2016).

Em virtude da intensificação do processo urbano, as áreas mais centrais da cidade apresentam poucos espaços vegetados. Em contrapartida, a classe "vegetação" configura $52,09 \%$ do perímetro urbano, e localiza-se nas áreas mais periféricas da cidade, sobretudo, na região oeste/sudoeste, em que há as maiores extensões de vegetação, em virtude dos parques. É oportuno mencionar que há um processo de expansão urbana em direção a serra do Mel, que tende a propiciar surgimento de problemas ambientais.

A densidade construtiva mais elevada está concentrada nas áreas mais centrais, principalmente nas regiões de planejamento do Santos Reis, Centro e Maracanã. Essas áreas possuem pouca presença de vegetação natural e apresentam-se com maior intensidade os efeitos do processo urbano, influenciando diretamente na especulação imobiliária.

\section{Análise do Potencial de Uso do Solo Urbano}

Com base no cruzamento dos produtos analisados anteriormente, buscou analisar o potencial de uso do solo urbano. Este mapeamento foi dividido em três classes: áreas não adequadas, adequadas e áreas potenciais. Salienta-se que estas classes tiveram como base os estudos de Franco et al. (2011) e Souza et al. (2014).

Conforme visualizada na Figura 6, a classe de áreas não adequadas, possui predominância nas regiões circundantes a noroeste, sudeste, sul e oeste da cidade. Essas áreas apresentam as maiores elevações e declividades. E dessa forma, não beneficiam o processo de edificação. O processo de urbanização nessa região pode ser danoso ao meio ambiente, haja vista que são nessas regiões que predominam a vegetação nativa.

Mesmo com as instabilidades identificadas nesses lugares, a valorização dada às áreas verdes nos espaços urbanos tem contribuído para que ocorra o aumento de edificações e condomínios para moradores de alta renda nas regiões com predominância de vegetação (ARAÚJO et al., 2019; SANTANA et al., 2020). Essas áreas são exploradas pelos agentes imobiliários, que elevam o preço dos imóveis devido à presença de amenidades ambientais, segurança e lazer (SOUZA e JÚNIOR, 2017). 
Em contrapartida, na região do Santos Reis, localizada a noroeste, moradores ocupam áreas de encostas e possuem imóveis com estruturas físicas frágeis. A impermeabilização do solo e a retirada da vegetação contribui para a ocorrência de enchentes. Essa região é residida por uma população de baixa renda, onde os imóveis são construídos em lugares inapropriados e apresentam estruturas frágeis (SILVA, 2019).

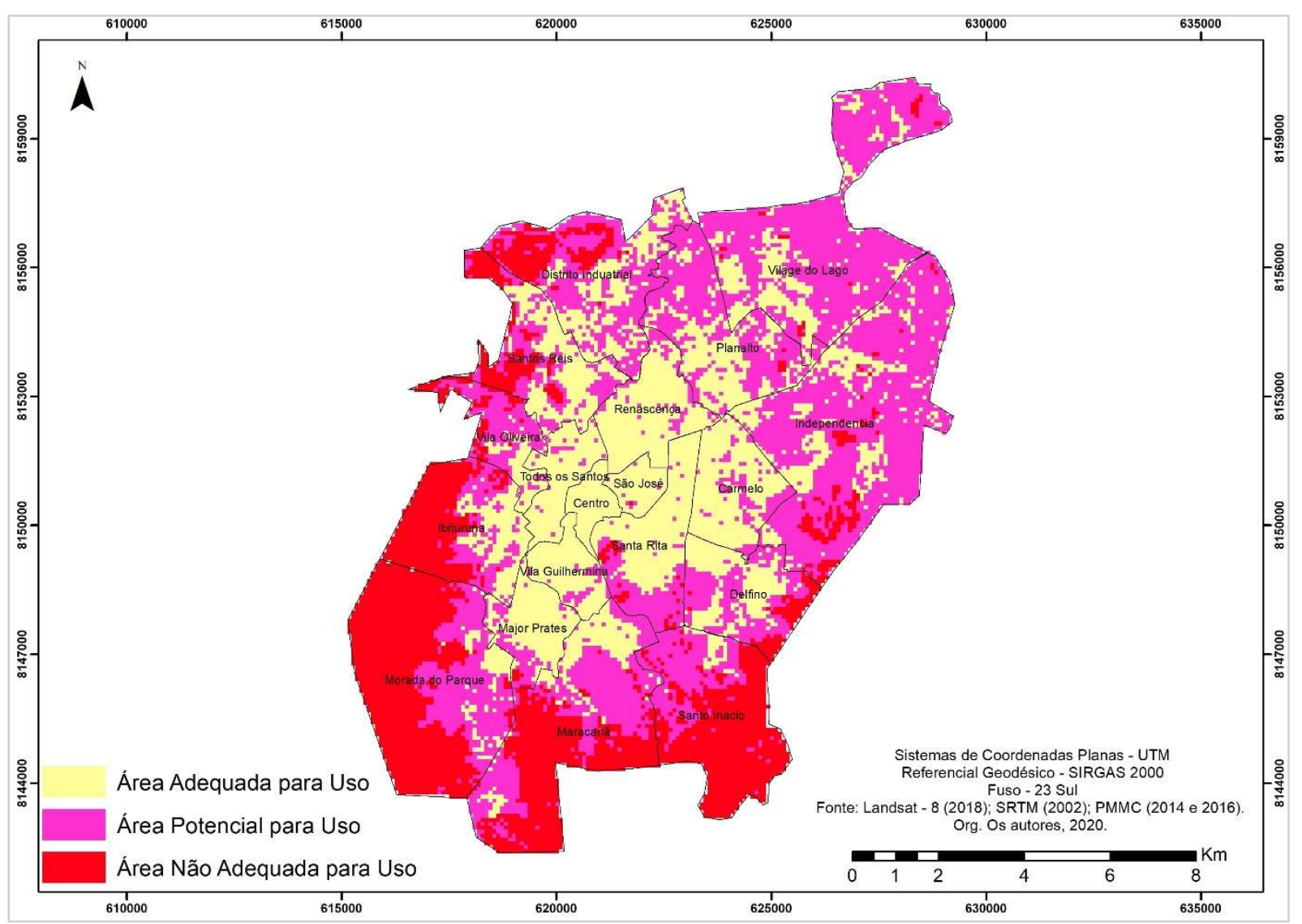

Figura 6 - Potencial de Uso do Solo Urbano. Fonte: Os autores, 2020.

Com base no trabalho de campo, observou-se essas constatações supracitadas, sobretudo na Região do Ibituruna, em específico no condomínio Serra do Mel. Foram identificadas casas de elevado padrão arquitetônico inseridas em áreas com predominância de vegetação nativa sobretudo mata seca, as quais estão em relevo fortemente ondulado, visualizada na fotografia A da Figura 7. Ainda notou-se que existem pontos de desmatamento na Serra do Mel, principalmente com proximidade dos imóveis visualizada na fotografia B, Figura 7. 


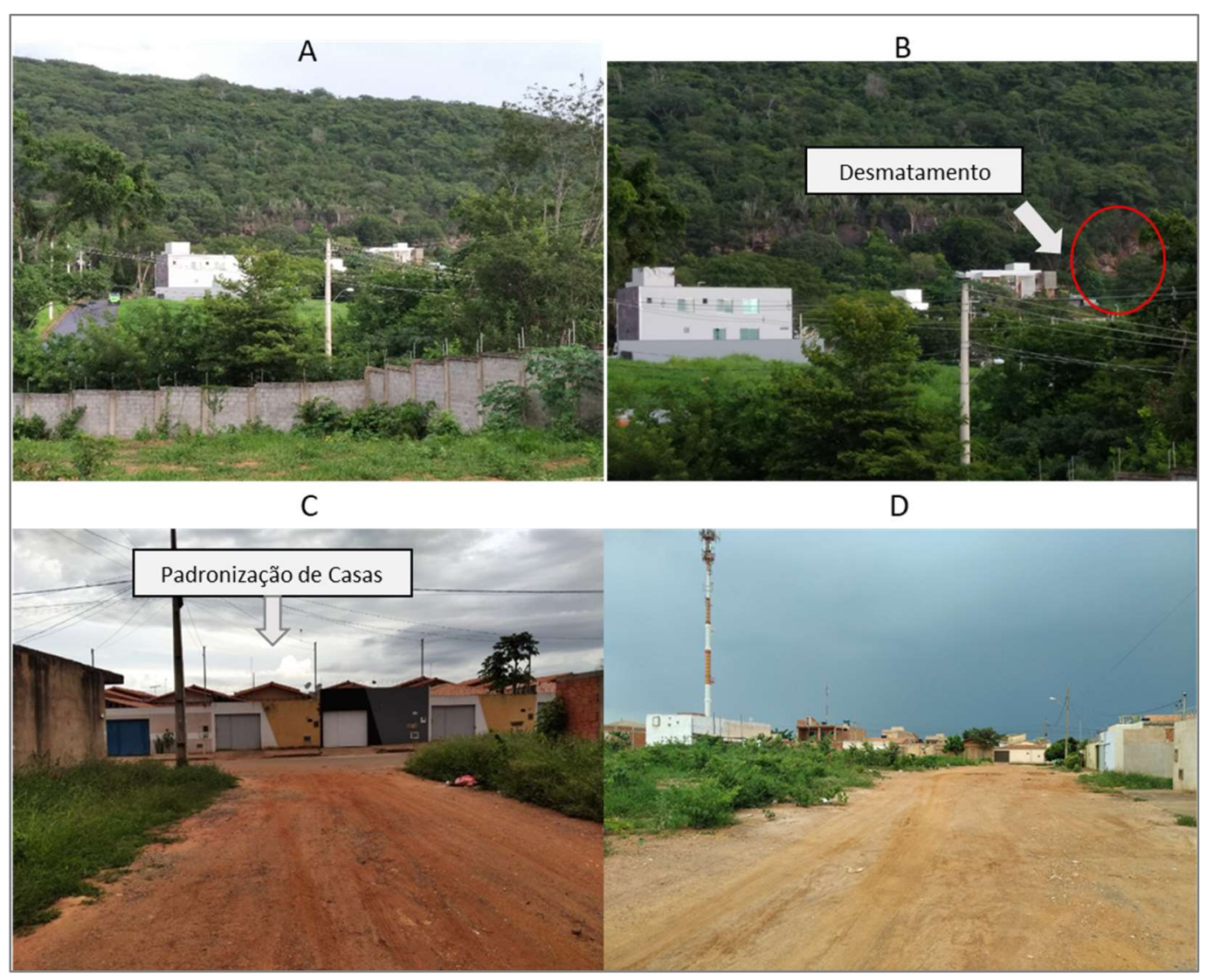

Figura 7 - Pontos de Análise em Campo. Fonte: autores, 2020.

A classe com áreas adequadas para uso do solo urbano, encontra-se nas regiões centrais de Montes Claros. Esses lugares possuem o relevo mais plano, e é onde ocorre a maior ocupação. Em virtude do intenso uso dessas áreas para atividades urbanas, as áreas verdes são escassas. Assim, a utilização dessas áreas já ocupadas, evitam que novas áreas sejam exploradas e que haja o desmatamento e o agravamento das condições ambientais. Observando-se mais espaços vazios. Na região do Centro apresenta maior concentração de atividades urbanas, como comércio em inúmeros segmentos, serviços de saúde, bancários e outros. E possui a maior integração de vias de acesso, que liga todas as partes extremas da cidade ao centro. Portanto, configura-se como uma área adequada para ocupação, devido as suas características físicas e sua oferta de serviço (FRANÇA, 2007).

As áreas potenciais estão nas regiões periféricas, principalmente no sentido norte e nordeste. Essas regiões possuem pouco adensamento construtivo, com espaços vagos que proporcionam o investimento a construção. As áreas potenciais estão em regiões de planejamento que possuem baixo valor de terra, devido à localização, acesso restrito e 
condições ambientais ruins, como pouca arborização, que favorece a temperaturas elevadas, ar mais poluído e degradação da paisagem urbana (MEIRELES e CASTRO, 2017).

Esses lugares são pouco valorizados pelo mercado imobiliário, o qual delimita espaços da cidade de acordo com o interesse do capital (REBOUÇAS e MOURAD, 2019). Devido ao preço de terra barato, as regiões norte e nordeste da cidade foram foco de investimento de construtoras que se beneficiaram com o lucro gerado com a venda dos imóveis, que visavam o público de baixa renda. E também foram alvos para construção de casas populares do programa Minha Casa Minha Vida (BATISTA et al., 2019).

Assim, essa área de estudo não apresenta aspectos atrativos para os agentes imobiliários e empresários, pois, possui predominância de residências de baixo padrão econômico, bem como concentração de população de baixa renda, além da falta de pavimentação em determinados pontos. Dentre os atrativos para o setor imobiliário, cita-se as áreas verdes, e nas regiões em que há espacialização dessa classe, com potencial de uso, não se observou predominância desse aspecto.

Do ponto de vista das condições ambientais, nota-se que as áreas potenciais de uso urbano, apresentam ondulações geomorfológicas amenas, densidade construtiva baixa e área vegetada que não corresponde a nenhuma área de proteção, o que torna essas extensões propícias à novas ocupações, principalmente por não infringirem áreas protegidas do ponto de vista ambiental.

\section{Considerações Finais}

Com base no mapeamento do potencial do uso do solo urbano na cidade de Montes Claros, foram identificados um cenário preocupante do ponto de vista do uso do solo. $\mathrm{O}$ ponto mais crítico observado foi destinado à classe "áreas não adequadas para uso do solo urbano", sobretudo na porção sudoeste, visto que, possuem condomínios espaçados nas extensões da Serra do Mel, área esta que se enquadra na Lei de Área de Proteção Permanente - APP.

Ainda diante do mapeamento realizado, constatou-se que "áreas potenciais ao uso do solo urbano", estão predominantemente distribuídas nas porções nordeste e norte da cidade de Montes Claros, e, chama-se atenção para os aspectos favoráveis diante da 
legislação ambiental, pois são áreas que se habitadas, cumprirão o código florestal, pois não situam-se em declividade acentuadas.

Conclui-se mencionando que, as técnicas aplicadas nesse trabalho nortearam de maneira objetiva áreas que merecem atenção do ponto de vista ambiental, bem como extensões propícias para novas ocupações na Cidade de Montes Claros, que obedecem os regulamentos ambientais. Este estudo pode contribuir para análises futuras em outras áreas de abordagens, sobretudo pela acessível execução dos procedimentos operacionais, bem como o acesso gratuito dos materiais.

\section{Referências}

AMARAL, Cinthia Maria; REIS, Claudio Henrique. Suscetibilidade a escorregamentos e inundações: hierarquização dos graus de riscos na área urbana de Viçosa-MG. Revista da ANPEGE, v. 13, n. 21, p. 199-219, 2017.

ARAÚJO, Douglas Cavalcante; DE LIMA MARQUES, Ailson; MOURA, Debora Coelho. Descentralização urbana e expansão imobiliária em áreas ambientalmente vulneráveis de Campina Grande-PB. Revista de Geociências do Nordeste, v. 5, p. 49-56, 2019.

BATISTA, Ramony Pereira; PEREIRA, Anete Marília; BORTOLO, Carlos Alexandre. Segregação Socioespacial e os Espaços Residenciais Fechados em Cidades Médias/Socioespacial Segregation and Gated Communities in Medium Size Cities. Caderno de Geografia, v. 29, n. 58, p. 847-866, 2019.

BOLAY, Jean-Claude. When Inclusion Means Smart City: Urban Planning Against Poverty. In: Proceedings of the Future Technologies Conference. Springer, Cham, 2019. p. 283 299.

BOLAY, Jean-Claude; KERN, Abigaïl-Laure. Intermediate cities. The Wiley Blackwell Encyclopedia of Urban and Regional Studies, p. 1-5, 2019.

BORIN, Camila Parachini F.; MEIRELES, Eduardo. Arenas Urbanas: O capital na contramão das cidades sustentáveis/Urban Arenas: The capital against the sustainable cities. Brazilian Journal of Development, v. 6, n. 1, p. 1097-1102, 2020.

CAMPOS, Ertz Ramon Teixeira et al. Breve histórico da educação a distância no Brasil e do Cead-Unimontes: rompendo limitações geográficas para atender às aspirações dos estudantes e promover ensino, pesquisa e extensão. Revista Intercâmbio, v. 13, p. 40-50, 2019.

CAMPOS, Sérgio; CAMPOS, Marcelo; NARDINI, Rafael Calore. Caracterização da capacidade de uso das terras de uma microbacia no interior paulista. Nativa, Sinop, v.4, n.5, p.328-332, 2016. 
Cruz, Priscila Karolline Rodrigues, Vieira, Maria Aparecida, Carneiro, Jair Almeida, Costa, Fernanda Marques da, \& Caldeira, Antônio Prates. (2020). Dificuldades do acesso aos serviços de saúde entre idosos não institucionalizados: prevalência e fatores associados. Revista Brasileira de Geriatria e Gerontologia, 23(6), e190113. Epub January $13,2020$.

FRANÇA, Iara Soares de. A cidade média e suas centralidades: o exemplo de Montes Claros no norte de Minas Gerais. 2007. 283 f. Dissertação (Mestrado em Ciências Humanas) - Universidade Federal de Uberlândia, Uberlândia, 2007.

FRANÇA, Iara Soares; ALMEIDA, Maria Ivete Soares. O processo de verticalização urbana em cidades médias e a produção do espaço em Montes Claros/MG. Boletim Gaúcho de Geografia, v. 42, n. 2, 2015.

FRANÇA, Iara Soares; BARBOSA, Roméria Soares. EXPANSÃO DE HABITAÇÃO DE INTERESSE SOCIAL: O PROGRAMA MINHA CASA MINHA VIDA EM MONTES CLAROS/MG. Revista de Geografia (Recife), v. 36, n. 3, 2019.

FRANÇA, Iara Soares; SOARES, Beatriz Ribeiro. Expansão urbana em cidades médias: uma reflexão a partir do núcleo e da área central de Montes Claros no Norte de Minas Gerais. Geo UERJ, v. 2, n. 17, p. 47-63, 2007.

FRANCO, Avílio A.; RESENDE, Alexander Silva; CAMPELLO, Eduardo FC. Importância das leguminosas arbóreas na recuperação de áreas degradadas e na sustentabilidade de sistemas agroflorestais. In: Embrapa Caprinos e Ovinos-Artigo em anais de congresso (ALICE). In: SEMINÁRIO SISTEMAS AGROFLORESTAIS E DESENVOLVIMENTO SUSTENTÁVEL, 2003, Campo Grande, MS. Palestras... Campo Grande: Embrapa Gado de Corte; Dourados: Embrapa Agropecuária Oeste; Corumbá: Embrapa Pantanal, 2003. 24 f. 1 CD ROM., 2011.

GALVÃO, Luciana Gomes Marques. Produção do espaço urbano na Serra do Mel por condomínios fechados em Montes Claros-MG. 2018. 147f. Dissertação (Mestrado em Geografia) - Universidade Federal de Minas Gerais, Belo Horizonte, 2018.

INSTITUTO BRASILEIRO DE GEOGRAFIA E ESTATÍSTICA - (IBGE). Divisão Regional do Brasil em Regiões Geográficas Imediatas e regiões Geográficas Intermediárias. Coordenação de Geografia. - Rio de Janeiro: IBGE. 2017.

LEITE, Manoel Reinaldo; SILVA, Lucas Augusto; DE MAGALHÃES FILHO, Raul. Análise do comportamento da temperatura de superfície e fluxo de calor no solo: Um estudo de caso no perímetro urbano de Montes Claros, Minas Gerais. Espaço Aberto, v. 8, n. 1, p. 109-125, 2018.

LEITE, M. E. Geotecnologias aplicadas ao mapeamento do uso do solo urbano e da dinâmica de favela em cidade média: o caso de Montes Claros-MG. Tese (Doutorado em Geografia) - Instituto de Geografia, Universidade Federal de Uberlândia, Uberlândia, MG, 2011 . 
LEITE, Marcos Esdras et al. MAPEAMENTO DAS FITOFISIONOMIAS DO CERRADO NO NORTE DE MINAS GERAIS. Revista de Geografia-PPGEO-UFJF, v. 8, n. 1, 2018.

LEITE, Marcos Esdras et al. Monitoramento da dinâmica no uso do solo urbano de Montes Claros. Caminhos de Geografia, v. 15, n. 51, p. 172-180 2014.

LEITE, Marcos Esdras. Geoprocessamento aplicado ao estudo do espaço urbano: o caso da cidade Montes Claros / MG. 2006. 118 f. Dissertação (Mestrado em Ciências Humanas) - Universidade Federal de Uberlândia, Uberlândia, 2006.

LEITE, Marcos Esdras; BATISTA, Ramony Pereira; CLEMENTE, Carlos Magno Santos. Segregação espontânea na cidade de Montes Claros/MG: Uma análise auxiliada pelo Sensoriamento Remoto. Geoambiente On-line, n. 15, p. 01-25 pág., 2010.

LIMA, Pedro Henrique Godeiro et al. Desastre socioambiental e ordenamento territorial no bairro Mãe Luíza, Natal-Rio Grande do Norte (RN), Brasil. Territorium, n. 27 (I), p. 37 49, 2020.

MEIRELES, Eduardo; CASTRO, Carolina Maria Pozzi de. Provisão do Programa Minha Casa, Minha Vida em São José do Rio Preto, SP: inserção urbana e adequação socioeconômica e ambiental-um estudo de caso do conjunto habitacional Nova Esperança. Ambiente Construído, v. 17, n. 3, p. 219-233, 2017.

NEMIROVSKY, Andressa Karen da Silva; NEVES, Luciana Viana; COUTO, Manoel Fernandes. Análise da distribuição espacial de deslizamentos no município de Petrópolis (RJ) entre 1940 a 2015. Revista Continentes, n. 13, p. 85-96, 2019.

OLIVATO, Débora; JUNIOR, Humberto Gallo. Evolução da participação social na legislação brasileira sobre gestão de riscos ambientais. Territorium, n. 27 (I), p. 155-166, 2020.

PEDRON, Fabrício de Araújo et al. Utilização do sistema de avaliação do potencial de uso urbano das terras no diagnóstico ambiental do município de Santa Maria-RS. Ciência Rural, v. 36, n. 2, p. 468-477, 2006.

PREFEITURA MUNICIPAL DE MONTES CLAROS. Diário Oficial Eletrônico: 19-0516. 2016. Diário Oficial Eletrônico. Disponível em: http://www.montesclaros.mg.gov.br/diariooficial/2016/mai16/Di\%C3\%A1rio\%20Oficial\%20Eletr\%C3\%B4nico\%2019-05-16.pdf. Acesso em: 13 jul. 2020.

REBOUÇAS, Thaís; MOURAD, Laila Nazem. Operações urbanas consorciadas e a manifestação de interesse privado em Salvador: o regramento da cidade de exceção. In: GOMES, Hortênsia; SERRA, Ordep; NUNES, Débora (Orgs.). Salvador e os descaminhos do Plano Diretor de Desenvolvimento Urbano: construindo novas possibilidades. Salvador: Edufba, 2019.

REIS, Igor; FERNANDES, Carlos Eduardo; DE ARAÚJO FERNANDES, Laila Isa Faustino. Ocupação urbana: uso desordenado dos recursos hídricos no córrego João Cesário 
em Anápolis-GO/Urban occupation: miscellaneous use of water resources in João Cesario Stream in Anápolis-GO. Brazilian Journal of Development, v. 6, n. 1, p. 1116-1137, 2020.

RIFFEL, Eduardo Samuel; RUIZ, Luiz Fernando Chimelo; GUASSELLI, Laurindo Antonio. Mapeamento de suscetibilidade a deslizamentos a partir de mineração de dados e do modelo SHALSTAB. Revista Brasileira de Cartografia, v. 68, n. 9, 2016.

RODRIGUES, Fernando Rua; DO NASCIMENTO LOPES, Elfany Reis; LOURENÇO, Roberto Wagner. ANÁLISE INTEGRAL DOS IMPACTOS URBANOS EM ÁREAS VERDES: UMA ABORDAGEM EM SOROCABA, BRASIL. Raega-O Espaço Geográfico em Análise, v. 46, n. 2, p. 135-151, 2019.

SANTANA, Julliana Rocha et al. Segregação urbana na cidade de Major Izidoro: o caso do Bairro de Fátima em comparação com o loteamento Terra do Leite. Diversitas Journal, v. 5 , n. 1, p. 270-282, 2020.

SANTOS, Wanderson Oliveira; FERRAZ, Ana Emília De Quadros. Urbanização e produção do espaço urbano em Vitória da Conquista-BA: novas formas e conteúdos/Urbanization and production of urban space in Vitória Conquista-BA: new forms and contents. Brazilian Journal of Development, v. 6, n. 1, p. 729-740, 2020.

SILVA, Francielle Gonçalves. Análise integrada da vulnerabilidade ambiental: risco de movimento de massa na cidade de Montes Claros/MG. Revista Okara, v.13, n.2, 2019.

SILVA, Renato Ferreira. Análise dos impactos ambientais da Urbanização sobre os recursos hídricos na sub-bacia do Córrego Vargem Grande em Montes Claros-MG. Caderno de Geografia, v. 26, n. 47, p. 966-976, 2016.

SILVA, Tatiana Acácio et al. Mapeamento da fragilidade ambiental na bacia hidrográfica do rio Candeias, RO. Journal of Environmental Analysis and Progress, v. 5, n. 1, p. 058-068, 2020.

SILVA, Tatiana Acácio et al. Mapeamento da fragilidade ambiental na bacia hidrográfica do rio Candeias, RO. Journal of Environmental Analysis and Progress, v. 5, n. 1, p. 058068, 2020.

SILVERMAN, Bernard W. Density estimation for statistics and data analysis. CRC press, 1986.

SIMÕES, L. S. A.; MARTINS, J. E. S.; VALERIANO, C. M.; GODOY, A. M.; ARTUR, A. C. Folha Vargem Bonita: SF.23-V-B-I. Programa Mapeamento Geológico do Estado de Minas Gerais. Projeto Fronteira de Minas Gerais. CODEMIG. UFMG. Ago/2015.

SOUZA, Claudia-Virginia Cabral de, KLINK, Jeroen, DENALDI, Rosana. (2020). Planejamento reformista-progressista, instrumentos urbanísticos e a (re) produção do espaço em tempo de neoliberalização. Uma exploração a partir do caso de São Bernardo do Campo (São Paulo). EURE(Santiago), 46(137), 203-223.

SOUZA, Cristiano Marcelo Pereira et al. Avaliação do Potencial de Uso Urbano da Cidade de Ilhéus-BA. Revista Brasileira de Geografia Física, v. 7, n. 01, p. 165-179, 2014. 
SOUZA, Cristiano Marcelo Pereira et al. Avaliação do Potencial de Uso Urbano da Cidade de Ilhéus-BA. Revista Brasileira de Geografia Física, v. 7, n. 01, p. 165-179, 2014.

SOUZA, Mikaelly Oliveira; DA SILVA JÚNIOR, Otoniel Fernandes. Os condomínios fechados e a produção do espaço urbano em Mossoró: segregação e acumulação do capital imobiliário. PENSAR GEOGRAFIA, v. 1, n. 1, p. 7-27, 2017.

TEIXEIRA, Thiara Messias et al. Unidades geoambientais e modificações no uso do solo do município de Formosa-GO. Revista Geográfica Acadêmica, v. 13, n. 2, p. 48-66, 2020.

UFV, CETEC; UFLA, FEAM. Mapa de solos do Estado de Minas Gerais. Universidade Federal de Viçosa. p. 49, 2010. 